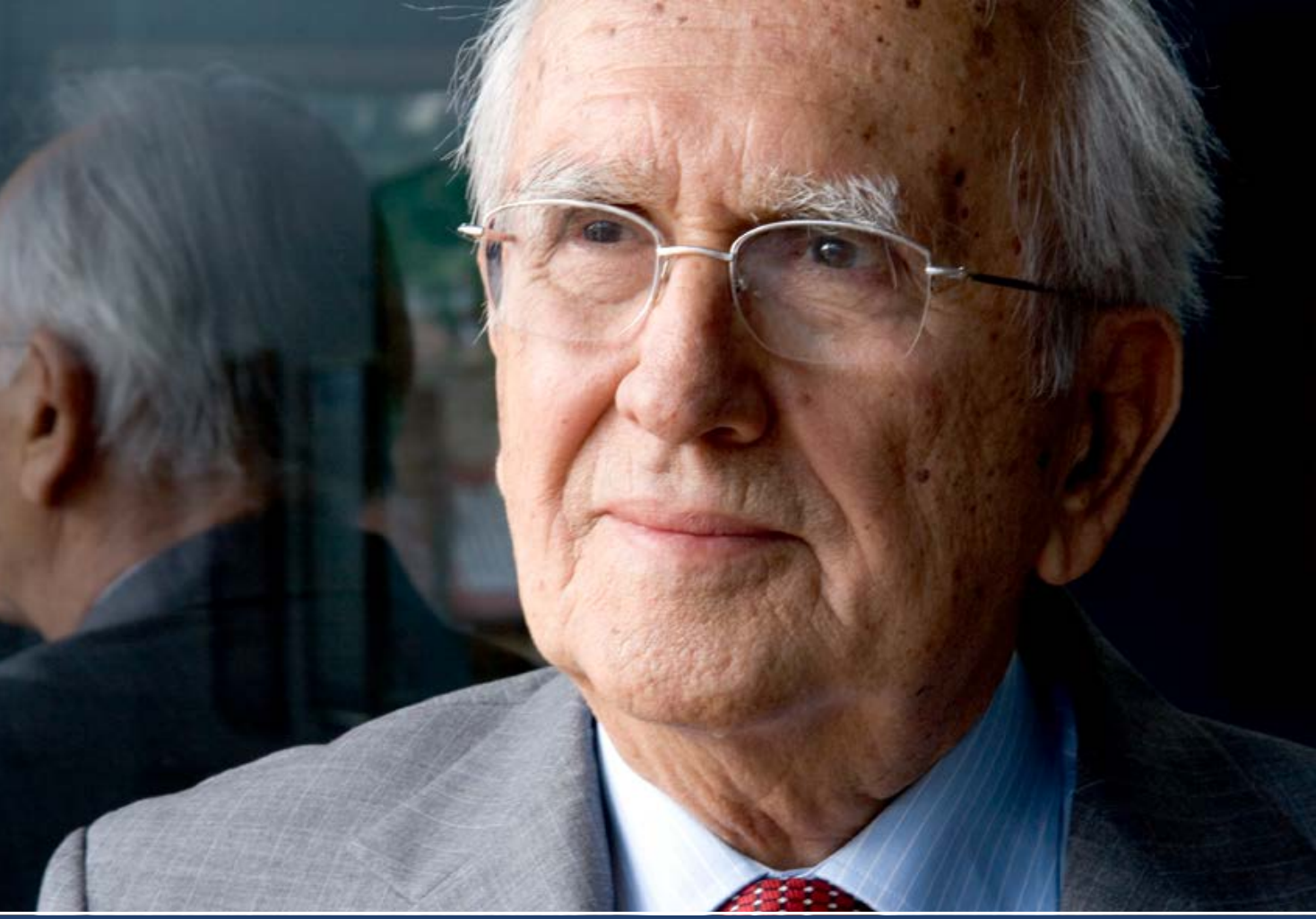

\title{
Doprinos Adila Zulfikarpašića oblikovanju mirovnog sporazuma za Bosnu i Hercegovinu s deset multietničkih provincija 1992. i 1993. u Ženevi
}

Prof. dr. Mirko Pejanović

129-134.

Adil Zulfikarpašić i liberalne političke inicijative ZBORNIK RADOVA 


\section{Doprinos Adila Zulfikarpašića} oblikovanju mirovnog sporazuma za Bosnu i Hercegovinu s deset multietničkih provincija 1992. i 1993. u Ženevi

\section{Prof. dr. Mirko Pejanović}

\section{Redovni član Akademije nauka i umjetnosti Bosne i Hercegovine pejanovicm@hotmail.com}

SAŽETAK: U diskusiji na temu doprinosa Adila Zulfikarpašića oblikovanju mirovnog sporazuma za Bosnu i Hercegovinu s deset multietničkih provincija 1992. i 1993. godine na Ženevskoj mirovnoj konferenciji rasvjetljavam, na temelju ličnog sjećanja, sve aktivnosti koje je on provodio u saradnji sa državnom delegacijom ratnog Predsjedništva Republike Bosne i Hercegovine u pripremi takvog mirovnog sporazuma. Adil Zulfikarpašić je bio veoma zainteresovan za odvijanje pregovora na Ženevskoj mirovnoj konferenciji. Samoinicijativno je pozvao državnu delegaciju da dođe u Zürich i da u Bošnjačkom institutu koristi izvore i građu za svoj rad. Jednog dana smo akademik Filipović i ja doputovali kod njega u Švicarsku. Potom su došli i drugi članovi delegacije. Na raspolaganju smo imali sve uslove za rad. Diskutovali smo o mogućim osnovama izrade mirovnog plana s deset multietničkih provincija. Glavno polazište za pripremu plana bila je Platforma o radu Predsjedništva Republike Bosne i Hercegovine u ratnim uslovima. Riječ je o tome da je Platforma definisala odredbe o unutrašnjem teritorijalnom ustrojstvu Bosne i Hercegovine. Po tim odredbama, unutrašnje državno ustrojstvo zasniva se na regionalnoj i lokalnoj samoupravi. Adil Zulfikarpašić je dijelio mišljenje o valjanosti odredbi Platforme. U njegovom Bošnjačkom institutu mogli smo koristiti sve historijske, ekonomske, kulturološke i druge izvore da sačinimo mirovni plan s deset multietničkih provincija. Adil Zulfikarpašić je, zahvaljujući svojim kontaktima s rukovodstvom Liberalne internacionale, dobio podršku za prijedloge državne delegacije Bosne i Hercegovine. To je umnogome utjecalo na $\mathrm{Da}$ vida Owena da prihvati prijedloge državne delegacije za mirovni plan s deset provincija, koje su imale multietničku strukturu prema Popisu stanovništva iz 1991. godine.

KLJUČNE RIJEČI: ženevska mirovna konferencija, Bosna i Hercegovina, plan s deset provincija, državna delegacija za pregovore na mirovnoj konferenciji, Bošnjački institut, Adil Zulfikarpašić 
Ovu sam temu najviše zasnovao na sjećanju na učešće Adila Zulfikarpašića u oblikovanju mirovnog sporazuma za Bosnu i Hercegovinu s deset multietničkih provincija 1992. i 1993. godine. Njegovo interesovanje je bilo veliko, neograničeno, a njegova brižnost prema Bosni i Hercegovini i njenoj sudbini u ratu i stradanju je, također, bila neograničena. Možda je to sudbina svih ljudi koji se odvoje od domovine, pa žive dalje, a onda dođu zle godine i boli sve, svaka informacija izaziva bol, usljed stradanja bošnjačkog naroda tokom agresije na Republiku Bosnu i Hercegovinu 1992-1995. godine. Želim dati opći okvir. Krajem ljeta 1992. godine započela je s radom u Ženevi mirovna konferencija za bivšu Jugoslaviju. Ona je bila posvećena traženju mirovnog političkog rješenja za zaustavljanje rata u Bosni i Hercegovini. Moderatori su u tom vremenu - septembru, oktobru, novembru, decembru 1992. i prvoj polovini 1993. godine - bili Cyrus Vance, visokorangirani zvaničnik Ujedinjenih nacija, te David Owen iz visokog ranga zvaničnika Evropske unije. Ratno Predsjedništvo Republike Bosne i Hercegovine je odlučilo da u septembru na razgovore o traženju mirovnog rješenja uputi u Ženevu svoju delegaciju, koja je tretirana kao državna, za razliku od druge dvije skupine, koje su slale svoje stranačke delegacije. Državnu delegaciju su činili Haris Silajdžić, ministar vanjskih poslova, Miro Lazović, predsjednik ratnog Parlamenta, Mariofil Ljubić, potpredsjednik Parlamenta, ja kao član ratnog Predsjedništva i akademik Muhamed Filipović kao predstavnik skupine opozicijskih partija koje su podržavale rad ratnog Predsjedništva.

Tamo smo došli u drugoj polovini septembra, i to putem koji nas je već na Igmanu mogao zaustaviti da ne idemo dalje i više ne budemo među živima, ali, eto, bilo je sreće. Naravno, razgovori naše delegacije s voditeljima pregovora su, a to je tehnika pregovora, bili u nekom suženom, zatvorenom dijelu. Njihov stručni čovjek je bio Ahtisaari. On je kasnije radio i za Kosovo. Potom su ponekad održavani i plenarni razgovori, gdje su bili svi, i Karadžićeva i Bobanova svita. Na tim razgovorima, koji su se skoro dva mjeseca odvijali, objašnjavali smo suštinu društveno-historijskog bića Bosne i Hercegovine, karakter rata, karakter agresije itd. Izlagali smo naše stanovište, koje smo usaglasili kao delegacija, da je osnova naših prijedloga suverenitet, nezavisnost i integritet države Bosne i Hercegovine, njene institucije i unutrašnje ustrojstvo na principima lokalne i regionalne samouprave, što je bilo u utemeljeno i u Platformi o radu Predsjedništva u ratnim uslovima. U prvom dijelu tih razgovora David Owen nas je obično dočekivao dosta ljut i nekooperativan, tvrdeći da ne vodimo računa o vojnom stanju na terenu. Pokazao je kartu, kao ona pokazuje gdje je šta. U to vrijeme, bio je to septembar 1992. godine, 70\% teritorije Republike Bosne i Hercegovine bilo je pod okupacijom Miloševićevog režima i Vojske Republike srpskog naroda. Mi nismo pristajali na tu formulu razgovora i tu ću stati. 
Želim kazati nešto o tome kako se Adil Zulfikarpašić zadesio s nama i otkud njegov doprinos da dođemo do našeg jednog koherentnog prijedloga za plan s deset provincija, koji je kasnije i usvojen. On je često dolazio u Ženevu i svaki put bi s nama razgovarao. Informisao bi se kako teku pregovori, šta se predlaže, šta se prihvata, a šta ne. Potom je s nama razmjenjivao mišljenja, u kojima je bio veoma blizak stanovištima državne delegacije ratnog Predsjedništva Republike Bosne i Hercegovine. Tu se on, zapravo, identifikuje s nekom vrstom ove naše, da kažemo, građansko-ljevičarske platforme, koja je ustanovljena u Platformi o radu Predsjedništva u ratnim uslovima. Drago mi je bilo čuti da je naš kolega profesor Nijaz Duraković Adila odmilja zvao Crveni Beg. On je, dakle, nama i pomogao da ne samo u bosanskim okvirima nego i u evropskom okruženju branimo ta stajališta. U neka doba smo se već približili tome da kao delegacija predložimo plan s unutrašnjim ustrojstvom koji upravo počiva na historijskom razvoju regija u Bosni i Hercegovini, koje su uvijek bile multietničke. Znaju se i podaci koliko je općina bilo jednonacionalnih u Bosni i Hercegovini. Sve druge su bile dvo- ili tronacionalne. Riječ je o tome da je cijela teritorija Republike Bosne i Hercegovine bila etnički mješovita. Jednoga dana Adil je rekao: „Znate šta? Vidim ja da radite u veoma teškim, skromnim uslovima. Predlažem da dođete u Zürich, u moj Institut, koristite dokumentacijsku osnovu, literaturu, a naročito ovu statističku osnovu, i uradite taj prijedlog." I onda smo otišli tamo, akademik Filipović i ja; drugi članovi su bili drugdje i mi smo za dva-tri dana to sastavili. Ako se bude opisivalo, pisalo i objavljivalo kako je nastajao mirovni plan s deset provincija, bit će zanimljivo podsjećanje na to. Mi smo, najprije, napravili plan sa 13 regija, a onda smo ih sveli na deset. I to je prihvaćeno. Bili smo veoma sretni zbog toga. Dakle, došli smo do koncepta regionalne unutrašnje teritorijalne strukture Bosne i Hercegovine, a naspram onoga čime nas je Owen stalno odbijao u razgovorima.

Uvidjeli smo da Adil ima stalnu komunikaciju unutar Liberalne internacionale. On je pomogao da se internacionaliziraju naši pregovori o bosanskom pitanju. Ovdje pod bosanskim pitanjem podrazumijevamo integritet države Bosne i Hercegovine. Adil Zulfikarpašić je imao podršku mnogih ljudi u Evropi. Neke razgovore smo imali priliku slušati. On je tražio da čujemo telefonske razgovore. Mislim da je to omekšalo Owena da prihvati takav prijedlog, koji podrazumijeva tri plus tri plus tri provincije i Sarajevo s posebnim statusom. Tri su bile s bošnjačkom većinom, tri sa hrvatskom, tri sa srpskom, ali sve su unutar sebe bile multietničke kakve su bile po popisu iz 1991. godine. I onda je u martu kopredsjedavajući mirovne konferencije formirao službeni prijedlog, koji je imao tri-četiri segmenta, među kojima je dokument o unutrašnjem ustrojstvu zasnovan na formiranju deset pro- 
vincija i Sarajeva s posebnim statusom. To je bilo otkravljivanje odnosa koji su prevladavali u pregovorima i na neki način zaustavljanja pritiska koji su u pregovorima vršili Karadžićeva i Bobanova skupina - da se „isključivo etnički podijeli teritorija! Ne može se živjeti zajedno, mora se tako napraviti! U Bosni je vijekovima prisutna mržnja." Nismo imali teškoće da na konferencijama za štampu to osporimo. E onda je, naročito zagrebačka štampa, a vidjeli smo to kad smo se vraćali za Sarajevo, objavila, valjda je negdje i sam Owen to rekao, da je prijedlog mirovnog plana sa deset provincija bio vrlo povoljan u to doba, da je za njega najviše osnova dala državna delegacija Bosne i Hercegovine, u kojoj su, tako tamo stoji, najbrojniji ljudi iz opozicijskih partija koji učestvuju ili pomažu rad Predsjedništva Republike Bosne i Hercegovine u ratnim uslovima. Šta se desilo s tim planom? Podržala ga je ratna Skupština Republike Bosne i Hercegovine i Predsjedništvo, uz samo jedan uslov, koji niko nije ni dovodio u pitanje - da se izbjeglice vrate u predratna mjesta življenja. Ovaj mirovni plan odbila je Skupština srpskog naroda, ona poznata jahorinska skupština, i to nakon što ga je Karadžić supotpisao. Plan je osporio Mladić na samoj skupštini.

Na kraju želim kazati da je doprinos Adila Zulfikarpašića u kreaciji ovog plana bio dragocjen, da je on, osim pomoći koju je pružio, imao velikog udjela i utjecaja na moćne ljude tadašnje Evrope da se prihvati koncept koji nije etnička podjela Bosne i Hercegovine. Nama je poslije Owen rekao da mu je jako žao što nije bilo dovoljno sloge u međunarodnoj zajednici da se izvrši pritisak na srpsku stranu da prihvati plan. Owen je govorio da je ovo najbolji plan za društveno-historijsko i multietničko biće Bosne i Hercegovine. Sad možete zamisliti: tada je bila raseljena Posavina, istočna Bosna i istočna Hercegovina, gradovi manje. Da je taj plan prošao, Bosna i Hercegovina ne bi doživjela ono što je kasnije doživjela: devastaciju, stradanje, genocid. Brže bi se obnovila, kao i svoju ukupnu društvenu i etničku strukturu. Međutim, to je dio historije o traženju mirovnog političkog rješenja u kojem je važan udio dao i Adil Zulfikarpašić. Prije nego što završim, uz još jednu zahvalu što sam imao priliku da se prisjetim ovoga, želim zamoliti upravu Bošnjačkog instituta u Bosni i Hercegovini da organizuje nekoliko naučnih konferencija, po mogućnosti s međunarodnim učešćem, izradom referata i zbornika, na tri teme, jer one pripadaju onome što je cijeli život radio Adil Zulfikarpašić. Prva je njegov odnos prema bosanskohercegovačkom društvu i državi Bosni i Hercegovini. Ima dragocjenih mjesta gdje on državnost Bosne i Hercegovine razumijeva onako kako su je zasnovali vijećnici ZAVNOBiH-a. Druga je odnos prema antifašističkom pokretu. Adil je iz istočne Bosne, u Drugom svjetskom ratu preživio je četnička klanja Bošnjaka na Drini. I treća tema je koncepcija bošnjaštva. Nikako da valorizujemo taj njegov dugi, tihi, uporni rad koji je nadvladao 
sve koncepcije i bio promovisan u ratnim uslovima. I čak četvrta tema - a tu imam malo više argumenata, ali neću izlagati - Bosna i Hercegovina je jedna od jugoslavenskih republika koja je kasnila u izvođenju političke pluralizacije i uvođenju višepartijskog sistema, što ju je jako koštalo. On je jedan od ljudi koji je nekako dizao krila da se krene u to. Ja sam bio, kao predsjednik Socijalističkog saveza Bosne i Hercegovine, učesnik nekih tadašnjih političkih procesa. Adil je dizao krila i oslobađao da se u to krene. Imao je stamenu političku misao o Bosni i Hercegovini, o pluralizaciji, o strankama. Vrijedilo bi da to šire spozna naša akademska zajednica i upozna naše odnose.

\section{Zaključak}

Ovo moje sjećanje uokvireno je sadržajem saradnje državne delegacije s Adilom Zulfikarpašićem tokom pripreme Vance-Owenovog mirovnog plana o deset provincija krajem 1992. i početkom 1993. godine.

Adil Zulfikarpašić je svekoliko doprinio političkoj pluralizaciji bosanskohercegovačkog društva. Kao izvrstan poznavalac liberalnodemokratskog koncepta u razvoju evropskih država, uzeo je učešća u aktivnostima za formiranje Stranke demokratske akcije. Njegovo neslaganje s njenim tadašnjim rukovodstvom i napuštanje SDA posebno je mjesto u političkoj biografiji Adila Zulfikarpašića. On je želio da Stranka demokratske akcije ima veći otklon od upliva religije u njen rad i razvoj. Uprkos tome, Adil Zulfikarpašić je u historijskom procesu pluralizacije bosanskohercegovačkog društva bio nosilac liberalnodemokratskih ideja. Njegova je velika zasluga vraćanje nacionalnog imena Bošnjaci umjesto Muslimani. 


\section{Adil Zulfikarpašićs's Contribution to Drafting of the Pe- ace Agreement for Bosnia \& Herzegovina Comprised of Ten Multi-ethnic Provinces in 1992 and 1993 in Geneva}

\begin{abstract}
In the discussion on Adil ZuIfikarpasic's contribution to drafting of the peace agreement for Bosnia o Herzegovina comprised of ten multi-ethnic provinces in 1992 and 1993, at the Geneva Peace Conference, I illuminate all the activities he carried out in cooperation with the state delegation of the wartime Presidency of the Republic of Bosnia and Herzegovina in the preparation of such a peace agreement. Adil Zulfikarpasic was very interested in the negotiations at the Geneva Peace Conference. On his own initiative, he invited the state delegation to come to $\mathrm{Zu}$ rich and use the sources and materials for their work at the Bosniak Institute. One day, academician Filipović and I arrived at his place in Switzerland. Then other members of the delegation came. We had all the working conditions at our disposal. We discussed the possible basis for drafting a peace plan with ten multi-ethnic provinces. The main starting point for the preparation of the plan was the Operational Platform of the Presidency of the Republic of Bosnia and Herzegovina in wartime conditions. It
\end{abstract}

is about the fact that the Platform defined the provisions on the internal territorial organization of Bosnia and Herzegovina. According to these provisions, the internal state structure is based on regional and local self-government. Adil Zulfikarpašić shared his opinion on the validity of the provisions of the Platform. At his Bosniak Institute, we were able to use all historical, economic, cultural and other sources to draw up a peace plan with ten multi-ethnic provinces. Thanks to his contacts with the leadership of the Liberal International, Adil Zulfikarpasic received support for the proposals of the state delegation of Bosnia and Herzegovina. This strongly influenced David Owen to accept the proposals of the state delegation for a peace plan with ten provinces, which had a multi-ethnic structure according to the 1991 Census.

Keywords: Geneva Peace Conference, Bosnia \& Herzegovina, ten provinces plan, state delegation for peace conference negotiations, Bosniak Institute, Adil Zulfikarpašić 